\title{
POSISI BAHASA ARAB DALAM DUNIA ISLAM
}

\author{
Muhlis Muhammad Abdullah \\ Sekolah Tinggi Agama Islam Negeri (STAIN) Sorong, Papua Barat, Indonesia \\ Jurusan Dakwah Program Studi Komunikasi Penyiaran Islam \\ Email :muhlismuhammadabdullah@gmail.com
}

\begin{abstract}
ABSTRAK
Posisi Bahasa Arab dalam dunia Islam salah satunya adalah Dakwah. Dakwah merupakan suatu bentuk komunikasi yang bertujuan amar ma'ruf dan nahi munkar dengan objek dakwah, mad'u, baik berupa individu maupun kelompok. Dakwah dalam Islam mencakup masalah aqidah, syariah, muamalah, dan akhlaq.Al-Qur'an dan Al-Hadist adalah dasar dakwah, jika Da'i tak beracuan kepada keduanya bisa jadi dakwah takkan bisa tersampaikan.Demi kesuksesan dalam berdakwah, Da'i diharuskan memahami materi yang ingin disampaikan dengan dasar Al-Qur'an dan Al-Hadist.Semua itu bertujuan agar dalam penyampaian materi dakwah tidak terjadi kesalahpahaman yang diterima oleh mad'u dalam menerima pesan-pesan yang disampaikan oleh seorang Da'i.
\end{abstract}

\section{PENDAHULUAN}

Bahasa Arab merupakan salah satu bahasa mayor didunia yang dituturkan lebih dari 200.000.000 umat manusia.Bahasa ini digunakan secara resmi oleh kurang lebih 20 negara. Dan karena ia merupakan bahasa kitab suci dan tuntunan agama umat Islam sedunia, maka tentu saja ia merupakan bahasa yang paling besar signifikannya bagi ratusan juta muslim sedunia, baik yang berkebangsaaan Arab maupun bukan kebangsaan Arab.

Bahasa Arab juga, merupakan bahasa yang selalu menjadi prioritas bagi semua Negara didunia.Ssebagian dari universitas dieropa menjadikan bahasa Arabsebagai salah satu mata kuliah yang wajib diikuti, karena peran bahasa Arab dalam perkembangan dunia tidak bisa dipungkiri lagi.

Posisi bahasa Arab dalam dunia Islam, salah satunya dalam dunia dakwah.Seorang Da'i harus memahami Bahasa Arab sebelum memulai berdakwah.Karena aturan-aturan dalam Al-Qur'an dan Al-Hadist menggunakan bahasa Arab.

Bahasa Arab juga merupakan bahasa dari Al-Qur'an, karena secara jelas al-quran meletakkan keutamaan terhadap bahasa Arab. Didalam Q.S. Yusuf : 2. yang 
artinya:"Sesungguhnya kami menurunkannya berupa al-Quran berbahasa Arab, agar kamu mengerti”.

Ada 3 alasan kenapa kita harus memperlajari bahasa Arab, alas an tersebut yakni:

1. Lughatul Islam (Bahasa Islam)

2. Lughatul Muslimin (Bahasa Kaum Muslimin)

3. Lughatul Ilmiyah (Bahasa Ilmu Pengetahuan)

Begitu istimewanya bahasa Arab ini, sekiranya penulis tertarik untuk membahasnya dalam tulisan ilmiyah ini.

\section{BAHASA ARAB DAN ISLAM}

Sebagai bahasa yang hidup, bahasa Arab, baik klasik maupun modern memiliki peranan yang sangat penting dalam agama Islam.Islam adalah agama wahyu yang diturunkan kepada nabi Muhammad SAW, sebagai utusan terakhir dengan perantara malaikat jibril.Wahyu yang Allah turunkan kepadanya menggunakan bahasa Arab dan dihimpun menjadi kitab suci al-quran.Begitu juga dengan hadist yang merupakan penjelasan dan penafsiran al-Quran dihimpun dan disusun dalam bahasa Arab.Al-Quran dan Al-hadist adalah pedoman bagi seluruh umat Islam, jadi penguasaan bahasa Arab itu sangat diperlukan.

Seiring dengan timbulnya berbagai masalah keagamaan setelah nabi Muhammad SAW wafat, dengan demikian Al-Quran dan Al-hadist dijadikan sebagai patokan hukum dalam Islam. Bahasa Arab selain sebagai bahasa lisan, ia juga bahasa tulisan. Bahasa tulisan inilah yang telah membangun tradisi ilmiah dikalangan umat Islam.

Sebagai bukti, banyak karya besar dibidang tafsir yang sangat membantu memecahkan masalah-masalah dalam Islam.Semua tertulis dalam bahasa Arab, demikian juga didalam bidang hadist, dan dibidang ilmu-ilmu keIslaman yang lainnya.Karena sumber-sumber asli ajaran Islam adalah bahasa Arab, maka sangatlah penting bagi umat Islam terutama kalangan ilmuannya untuk mempelajarai dan memahami serta menguasai bahasa Arab.

Selanjutnya, penggunaan bahasa Arab yang sangat fenomenal dalam agama tampak jelas dalam pelaksanaan ibadah ritual seperti ungkapan untuk memanggil atau mengajak 
shalat yang disebut adzan dan iqamat.Selain itu, bacaan-bacaan dalam shalat pun harus dilafadzkan dalam bahasa Arab.Dengan demikian, tidaklah salah jika ada yang mengatakan bahwa bahasa Arab adalah bahasa agama Islam.

Eksistensi bahasa Arab dalam dunia Islam begitu penting, karena bahasa Arab merupakan bahasa kunci ajaran-ajaran Islam yang tertuang dalam Al-Quran, Al-Hadist, dan kitab-kitab Tafsir, dan syarah hadist. Selain menjadi bahasa kunci ajaran Islam, bahasa Arab juga menjadi bahasa kunci pembuka khasanah ilmu pengetahuan agama dan saind yang sumber utamanya terdapat dalam kitab-kitab berbahasa Arab yang banyak dikaji oleh para ilmuan barat.

\section{BAHASA ARAB DAN AL-QUR'AN}

Al-Qur'an adalah wahyu Islam dan Islam adalah agaa Allah yang diturunkan kepada umat manusia. Pengetahuan mengenai pokok-pokok ajaran Islam yang tertuang seluruhnya dalam Al-Qur'an tidak akan bisa dipahami dengan baik kecuali dengan bahasanya.

Bahasa Arab, salah satu bahasa didunia, merupakan bahasa yang sangat penting karena terpilih menjadi bahasa Al-Qur'an yang dianggap sebagai kitab suci yang lengkap dan sempurna. Al-Qur'an adalah sebuah teks-teks lain dalam sejarah karena Al-Qur'an merupakan wahyu yang diturunkan Allah melalui malaikatnya kepada umat manusia.Eksistensi bahasa Arab sebagai bahasa alquan disebutkan Allah SWT dalam Surah Yusuf ayat 2, yang artinya :'Sesungguhnya kami telah menjadikan Al-Qur'an dalam bahasa Arab, supaya kalian berfikir”.

Al-Qur'an sebagai wahyu memiliki keistimewaan yang tak terbilang, diantaranya adalah bahwa Al-Qur'an yang notabene berbahasa Arab memiliki kaidah bahasa yang fasih dan mengandung gaya bahasa yang tak bisa tertandingi.

Ada 3 fungsi dan tujuan mengapa Al-Qur'an diturunkan dalam bahasa Arab.fungsi dan tujuan itu sekaligus merupakan keunggulan dan keutamaan menurut Al-Qur'an. Fungsi tersebut yaitu :

\section{Berfungsi Sebagai Sumber Informasi Dan Sumber Ilmu}


Allah berfirman dalam Q.S Al-Fushshilat : 2-3 yang artinya :(2) Diturunkan dari Tuhan Yang Maha Pemurah lagi Maha Penyayang. (3) Kitab yang dijelaskan ayatayatnya, yakni bacaan dalam bahasa Arab, untuk kaum yang mengetahui,

Selain itu, terdapat firman Allah SWT dalam Q.S. An-Nahl : 103 yang artinya : (103)Dan sesungguhnya Kami mengetahui bahwa mereka berkata: "Sesungguhnya Al-Qur'an itu diajarkan oleh seorang manusia kepadanya (Muhammad)". Padahal bahasa orang yang mereka tuduhkan (bahwa) Muhammad belajar kepadanya bahasa 'Ajam, sedang Al-Qur'an adalah dalam bahasa Arab yang terang.

Kata mengetahui dalam surah Al-Fushshilat menunjukkan penegasan fungsi dan tujuan diturunkannya Al-Qur'an dalam bahasa Arab.Al-Qur'an adalah kitab suci yang mengandung ilmu-ilmu yang tak terbatas, dan takkan bisa digai secara tuntas.Ilmu yang dikandungnya takkan pernah habis walau terus digali dan dikuras sepanjang masa, Al-Qur'an adalah sumber ilmu yang kaya dan abadi.

Ini artinya, yang menjadi sumber ilmu itu bukan Al-Qur'an yang kitab suci itu, tetapi juga bahasa Arab yang menjadi media kitab suci itu diturunkan.Al-Qur'an mewujud menjadi sumber ilmu, maka bahasa Arab juga menjadi sumber ilmu.Dengan demikian, dengan sebuah bahasa yang kayak ilmu, menjadi sumber informasi dan pengetahuan. (M. Anwar, Artikel Abatasa)

\section{Berfungsi Sebagai Sumber Intelegensi, Mencerdaskan}

Ada 2 ayat yang menegaskan ini, dalam Q.S. Yusuf : 1-2 dan Q.S. Az-Zukhruf : 1-3. Q.S. Yusuf ayat 2 yang artinya :(2) Sesungguhnya Kami menurunkannya berupa Al-Qur'an dengan berbahasa Arab, agar kamu memahaminya.Q.S. Az-Zukhruf ayat 1-3 yang artinya :(1) Haa Miim. (2) Demi Kitab (Al-Qur'an) yang menerangkan.(3) Sesungguhnya Kami menjadikan Al-Qur'an dalam bahasa Arab supaya kamu memahami(nya).

Didalam kedua ayat itu Allah SWT menegaskan, bahwa tujuan diturunkan dan dijadikannya Al-Qur'an berbahasa Arab adalah "agar kamu mengerti".Kata aqal dalam Al-Qur'anbermakna kecerdasan, sehingga mengapa Al-Qur'an diturunkan berbahasa Arab, di antaranya adalah agar kita cerdas.Bahasa Arab dalam Al-Qur'an berfungsi mencerdaskan para pembaca dan pengkajinya, dan tak luput dari bahasa Arab sebagai media yang menjadi ladang ilmu. 
Allah SWT mengungkapkan dua kata yang berbeda, berkaitan dengan Al-Qur'an berbahasa Arab itu.Pertama DIA mengungkapkan, "kami menurunkan”.Dan yang kedua DIA mengungkapkan, "Kami menjadikan" antara kata menurunkan dan menjadikan, tentu saja keduanya memiliki makna yang berbeda.

"Menurunkan" adalah sebuah aktivitas menggerakkan sesuatu dari atas ke bawah, yang berarti Al-Qur'an diturunkan dari alam yang tinggi kea lam yang rendan dengan bahasa Arab.sedangkan "Menjadikan" adalah sebuah tindakan menetapkan dan mengadakan sesuatu dari yang tidak ada menjadi ada, atau dari suatu kondisi ke kondisi lain yang dikehendaki. Ini berarti, bahwa keAraban Al-Qur'an adalah sebuah ketetapan yang Allah SWT kehendaki. (M. Anwar, Artikel Abatasa)

\section{Berfungsi Sebagai Dimensi Spiritual}

Q.S. Az-Zumar : 27-28 yang artinya :(27) Sesungguhnya telah Kami buatkan bagi manusia dalam Al-Qur'an ini setiap macam perumpamaan supaya mereka dapat pelajaran. (28) (Ialah) Al-Qur'an dalam bahasa Arab yang tidak ada kebengkokan (di dalamnya) supaya mereka bertakwa.

Dalam Q.S Az-Zumar : 27-28 juga dijelaskan bahwa Al-Qur'an berbahasa itu tujuannya adalah agar kita semua bertakwa. Tentu saja taqwa merupakan sebuah konsep yang sangat luas dan dalam.Tetapi secara garis besar, taqwa merupakan dimensi spiritual.

Banyak dari kalangan yang menceritakan pengalaman mereka ketika membaca Al-Qur'an mereka merasa damai, tenang, dan merasa dekat dengan Rabb.Bunyi dan nada bacaan Al-Qur'an membuat mereka hanyut dalam kedamaian.Itu artinya, AlQur'an dapat menggerakkan orang untuk menspiritualkan dirinya, untuk menjadi sosok yang mulia dan dekat dengan Penguasa dirinya.Al-Qur'an memiliki kekuatan untuk mendamaikan dan menenangkan, dan kekuatan itu muncul dari Al-Qur'an yang berbahasa Arab.

Bahasa Arab juga menjadi bahasa yang memiliki kekuatan untuk menspiritualkan manusia, membuat manusia cenderung pada kebaikan, berbeda dengan bahasa-bahasa lain.

Dari penjelasan diatas, Allah menurunkan Al-Qur'an dalam bahasa Arab bukanlah merupakan suatu hal yang kebetulan.Bahasa Arab merupakan bahasa yang 
strategis karena bahasa Arab berada di tengah-tengah dunia, selain itu juga bahasa Arab memiliki kekayaan kosa kata dan keseksamaan.

\section{POSISI BAHASA ARAB DIDUNIA ISLAM}

Penguasaan bahasa Arab merupakan hal yang penting.Mempelajari bahasa Arab adalah kewajiban untuk umat Islam, karena bahasa Arab adalah syarat dan alat untuk memahami ajaran Islam dengan lebih baik.

Menurut Ibn Khaldun "Bagi orang yang hendak memahami ilmu syariat Islam dia harus mengerti bahasa Arab dan ilmu-ilmu yang berkaitan dengannya, karena pengambilan hukum Islam dari Al-Qur'an dan Al-Sunnah tidak mungkin berhasil kecuali dengan bahasa Arab. begitulah yang diketahui dan dilakukan para cendikiawan dahulu dan hal yang demikian merupakan uswah khasanah bagi kita yang datang kemudian (Farhud 1983:7).

Menurut Imam As-Syafi'I beliau berkata setiap muslim wajib mempelajari bahasa Arab fusha, dia dapat memahami bacaannya dalam sholat. Dan Ibn Taimiah berpendapat bahwa yang menyebabkan terjadinya kekacauan dan tidak menentunya pegangan dalam agama ialah kurangnya pemahaman terhadap bahasa Arab.Selanjutnya beliau berkata, kesesatan pakar bid'ah bersumber dari kurang fahamnya mereka terhadap penggunaan bahasa Arab (Suhair 1999:56).

Abdul Rahman (2004) menyatakan bahwa pengembangan kurikulum mesti bermaksud sebagai pengembangan kurikulum yang bertitik tolak daripada kompetensi yang seharusnya dimiliki pelajar setelah menyelesaikan pendidikan.Guru-guru dituntun untuk dapat menyusun dan membuat rancangan pembelajaran yang berdasarkan kemampuan dasar dan dapat dikembangkan oleh anak didik.

Pendidikan merupakan syarat utama lahirnya generasi bangsa yang unggu dan kompetitif pada era global ketika ini.Namun sangat disayangkan pendidikan dinegara kita tercinta ini belum memiliki system pendidikan yang memungkinkan untuk menempatkan pendidikan sebagai keperluan yang penting untuk menghasilkan sumber daya manusia yang sesuai dengan cabaran zamannya.Untuk pendidikan yang kualitas mesti membutuhkan pengajar yang berkualitas juga.

Dakwah merupakan salah satu bentuk komunikasi dan seluruh agama disebarluaskan melalui komunikasi.Tanpa adanya komunikasi agama tidak mungkin bisa 
berkembang didunia ini.Itulah mengapa komunikasi dalam penyebaran agama Islam diistilahkan dengan dakwah.

Dakwah adalah suatu kajian dalam seruan, baik dengan lisan, tulisan atau tingkah laku yang dilakukan secara sadar dan berencana untuk mempengaruhi orang lain agar timbul suatu pengetian, kesadaran, penghayatan, serta pengalaman ajaran agama tan adanya unsure paksaan (M. Arifin, 1993:6).

Posisi bahasa Arab dalam dunia Islam salah satunya ada didalam dunia dakwah. Kecenderungan atas ilmu untuk saling menambah wawasan mengenai Islam, semakin menambah minat untuk terus mempelajari akan hal itu. Dakwah juga bertujuan untuk mengajak orang lain agar senantiasa mengamalkan apa yang diperintahkan oleh Allah SWT yang timbul dari kemauan mereka sendiri (Ahmad Mubarak, 2002:13).

Selain pengetahuan yang dalam mengenai kondisi dari lingkungannya, juru dakwah juga harus bisa berkomunikasi dengan masyarakatnya dengan baik. Unsur-unsur utama dalam dakwah meliputi: Da'i, Mad'u dan Materi Dakwah. Da'i adalah orang yang melakukan dakwah.Mad'u adalah manusia yang menjadi sasaran Dakwah.Sedangkan Materi Dakwah adalah isi dari pembahasan yang dibahas dalam kajian tersebut.

Banyak juga Da'i muda yang hadir saat ini, Seperti Ustadz Hannan Attaki, Ustadz Handi Bonny, Ustadz Salim Afillah, dan lain lagi.Seorang Da'i harus mampu membaca kondisi dan situasi Mad'u agar materi yang disampaikan mudah dipahami dan dilaksanakan oleh mad'u.Disinilah peran materi dakwah sangat dibutuhkan guna menunjang keberhasilan dalam berdakwah.

Jika membahas tentang posisi bahasa Arab didunia Islam, cukup luas saya rasa.Karena diera yang modern ini semua orang bisa mempelajari kapan saja dan dimana saja. Walau sebenarnya Bahasa Arab tergolong bahasa yang luas maknanya, tapi untuk umat muslim itu sangat mudah dipahami. Umat Islam sendiri menjadikan bahasa Arab sebagai bahasa penghubung antara manusia dengan Allah SWT. Walau sebenarnya Allah maha mengetahui apa saja yang kita katakan, tapi jika kita bisa menyampaikan menggunakan bahasa milik Allah SWT itu akan lebih bagus lagi. 


\section{KESIMPULAN}

1. Bahasa Arab secara kenyataan bukanlah bahasa khusus orang-orang muslim dan bukan satu-satunya bahasa agama Islam, tetapi bahasa Arab adalah bahasa yang paling dominan digunakan dalam Islam karena kaitannya dengan keberadaan Muhammad SAW sebagai orang Arab dan Al-Qur'an yang diturunkan dalam bahasa Arab.

2. Bahasa Arab adalah bahasa Al-Qur'an yang merupakan kitab suci agama Islam, dan merupakan sumber ajaran dan hukum Islam. Untuk memahami dan mengkaji isi dan kandungan Al-Qur'an dibutuhkan berbagai macam ilmu-ilmu yang berhubungan dengannya, seperti berbagai cabang ilmu tafsir, ushul fiqh, nahwu, balaghah, dll., yang kesemuanya itu tidak terlepas dari bahasa Arab.

3. Sementara posisi bahasa Arab dalam dunia Islam salah satunya dalam bidang dakwah. Dakwah digunakan pada Da'i untuk mengajak manusia ke jalan Allah SWT, jalan yang benar dan mengamalkan ajaran-ajaran Islam yang bersumber dari Al-Qur'an dan hadist. Keduanya merupakan sumber materi dakwah dan yang dapat dengan mudah dipahami dan dikaji dengan menggunakan bahasa Arab yang merupakan bahasa dari keduanya.

\section{DAFTAR PUSTAKA}

Izzan, A. (2007). Metodologi pembelajaran bahasa Arab. Bandung: Humaniora.

Wekke, I. S. (2014). Model Pembelajaran Bahasa Arab. Yogyakarta: Deepublish.

Wahida, B.(2015). Eksistensi Bahasa Arab Dalam Dunia Dakwah.Jurnal Dakwah AlHikmah, 75-90. 